Rosa Ventas Sastre

\title{
Tratamiento jurídico-penal de las imprudencias sanitarias con resultado de muerte o lesiones en el derecho español
}

La responsabilidad médica debe, en principio, ser proclamada cuando en el tratamiento médico, terapéutico o quirúrgico se incida en conductas descuidadas, que olvidando la lex artis, provoquen resultados lesivos.

\section{Consideraciones previas}

Han sido numerosas las aportaciones científicas sobre la doctrina general del Tribunal Supremo en materia de imprudencial. Por ello, a fin de evitar reiterarnos y extralimitarnos del tema objeto de estudio, hemos considerado más oportuno centrarnos, como piedra angular del presente trabajo, en el análisis de los aspectos más destacables de las imprudencias punibles en el ámbito de la actividad médico-sanitaria, con especial referencia a algunos de los casos más complejos enjuiciados por la Sala Segunda del Tribunal Supremo.

\section{El delito imprudente en la actividad sanitaria}

Según la más moderna doctrina científico-penal, el delito imprudente en la actividad sanitaria requiere en la estructura de su tipo los siguientes elementos: a) La inobservancia de los deberes objetivos de cuidado que impone la concreta actividad; b) La producción de muerte o lesiones; c) Una relación de causa a efecto entre la conducta del agente y el resultado dañoso producido; d) Imputación objetiva del resultado ${ }^{2}$.

En este sentido, debemos precisar que las infracciones dolosas se diferencian de las imprudentes no sólo en cuanto a la forma de culpabilidad, sino en que aquéllas admiten una imperfección del resultado querido, que en el caso de las imprudentes es impensable, ya que éstas sólo son punibles cuando se ha producido el resultado lesivo $\mathrm{y}$, en concreto, en el ámbito médico-sanitario éste debe ser de muerte o lesiones.

Por consiguiente, no es suficiente con la realización de una conducta imprudente, sino que además se exige la producción de un resultado material perjudicial, en la medida que nos hallamos ante un delito de resultado material ${ }^{3}$.

\section{II.1. La graduación de la imprudencia penal}

La diferenciación entre las figuras de imprudencia ${ }^{4}$ siempre ha sido una tarea ardua ${ }^{5}$. Ciertamente existe un vacío legal o ausencia de regla alguna eficiente que sirva para modular la imprudencia. Sin embargo, desde antaño tanto la doctrina como la jurisprudencia han tratado de esclarecer esta cuestión, señalando que la distinción radicaba en la intensidad de la culpa, no en el hecho de que se hubiesen vulnerado o no preceptos de carácter reglamentario ${ }^{6}$. A su vez, hacían depender la intensidad de la culpa de la gravedad de la desatención de la conducta, poniendo ambas, culpa y desatención, en correlación directa. ${ }^{7}$.

Hoy en día, las nuevas categorías legales de imprudencia grave y leve 8 , como señala la jurisprudencia más reciente $^{9}$, deben ser puestas en relación con la entidad de la infracción del deber objetivo de cuidado, idea vertebral del concepto de imprudencia, toda vez que el tipo del injusto de estas infracciones se estructura sobre el elemento normativo de la infracción de una norma de cuidado.

A mayor abundamiento, también se ha destacado la importancia de que el Tribunal analizase, no sólo la mayor o menor intensidad de la falta de atención o cuidado en la actividad, sino también la mayor o menor representación del evento previsible y evitable de la infracción del deber normativo ${ }^{10}$.

En realidad, la graduación de la imprudencia entra de lleno en el ámbito de lo valorativo y axiológico, vedado inexorablemente al Órgano judicial, que tendrá que actuar con un pleno criterio de relativismo, en atención al caso concreto y circunstancias concurrentes. En este sentido, ante la falta de postulados estrictamente técnicos, las resoluciones judiciales se apoyan principalmente en consideraciones de justicia, equidad o sentido común, cuando no en meras razones de oportunidad. Todo ello conlleva, como peligro inherente, la posibilidad de incurrir en soluciones jurisprudenciales arbitrarias o contradictorias; de ahí la importancia de analizar escrupulosamente todos los condicionamientos y circunstancias concurrentes en el supuesto enjuiciado. No obstante, no podemos obviar 
las dificultades con las que se enfrentan los Tribunales a la hora de fijar unos parámetros claros de resolución, ya que los elementos jurídicamente relevantes varían dependiendo del caso en concreto.

\section{II.2. La imprudencia profesional}

En cuanto a la denominada imprudencia profesionall ${ }^{11}$, si bien la doctrina de la Sala Segunda del Tribunal Supremo en un principio usó esta agravación en un sentido excesivamente rigorista, aplicándose a todo profesional por el mero hecho de serlo, posteriormente restringió este concepto, poniendo el acento más en la imprudencia misma que en la condición del sujeto activo ${ }^{12}$.

En cuanto a los requisitos que han de concurrir en el caso concreto para que se pueda apreciar imprudencia profesional, desde la Sentencia del Tribunal Supremo (Sala $2^{a}$ ) de 29 de diciembre de 1975 se establece una exigencia plural: 1. En cuanto al sujeto activo, la realización de actos negligentes en el ejercicio de su profesión, de la cual hace su medio de vida ordinario y dedicación laboral. 2. La conducta pertenece a la serie de actos que de manera habitual se exigen y practican por los profesionales del ramo. 3. Sobre el resultado, es precisa la producción de muerte o lesiones graves. 4 . En cuanto a la culpabilidad, es necesario que el resultado se produzca a consecuencia de impericia o negligencia profesional incompatible con la profesión, practicando ésta con manifiesta peligrosidad, caracterizada por un plus de culpa sobre la temeraria. 5. La apreciación de tales factores ha de realizarse con criterio de relatividad, ponderando, en todo caso, circunstancias, personas, y actividad profesional desarrollada.

La delimitación entre "imprudencia profesional"13 e "imprudencia del profesional"14 es esencial y trascendente, ya que sólo a la primera le es aplicable el plus agravatorio que señala el párrafo tercero del artículo 152 del vigente Código penal ${ }^{15}$. Ciertamente estos límites son confusos ${ }^{16}$, pero para apreciar tal agravación se ha exigido desde antaño que el resultado se origine a consecuencia de impericia o negligencia profesional ${ }^{17}$, inexcusable en su ejercicio, practicado éste con manifiesta peligrosidad. Esto es lo que representa el plus de agravación, pero, en ningún caso, debe operar de modo inmediato por el simple hecho de que la imprudencia provenga de un profesional.

\section{La doctrina jurisprudencial sobre los principios generales de la imprudencia médica}

La jurisprudencia ha elaborado una doctrina extensa y pormenorizada respecto de la imprudencia médica. Sobre este extremo, la Sentencia del Tribunal Supremo (Sala $2^{a}$ ) de 4 de septiembre de $1991{ }^{18}$ recoge un conjunto de principios generales sobre la materia, con independencia de los diferentes casos enjuiciados, que pueden resumirse en los siguientes: 1 . No se incrimina el error científico ${ }^{19}$. A mayor abundamiento, los errores de diagnóstico no son tipificables como infracción penal, salvo que por su entidad y dimensiones constituya una equivocación inexcusable $^{20}$. 2. Queda también al margen del ámbito penal la falta de extraordinaria pericia o cualificada especialización ${ }^{21}$. No obstante, debe sancionarse la equivocación inexcusable o la incuria sobresaliente, o cuando la falta de pericia sea de naturaleza extraordinaria o excepcio$\mathrm{nal}^{22}$. 3. La culpabilidad radica en que el facultativo pudo evitar el comportamiento causante del resultado lesi$v^{23}$. 4. En esta materia no se pueden establecer principios o generalizaciones inmutables ${ }^{24}$. La determinación de responsabilidad ha de efectuarse teniendo en cuenta las situaciones concretas sometidas al enjuiciamiento ${ }^{25}$, evitando las generalizaciones aplicables a todos los supuestos. 5. El deber de cuidado ha de establecerse primero, y posteriormente debe ser medido en función de todas las circunstancias concurrentes en el caso concreto, entre ellas la clase de actividad sobre la que se realiza el juicio de reprochabilidad, el riesgo o riesgos que comporta para las personas o las cosas, o la especialidad técnica o científica necesaria para el ejercicio profesional 26.6 . Si las deficiencias del instrumental médico no son imputables a los facultativos, o no consta que lo fueran, no puede apreciarse una conducta imprudente ${ }^{27}$.

\section{El riesgo no permitido como criterio de determinación de la infracción del deber objetivo de cuidado}

Como ya hemos destacado anteriormente, la imprudencia entra de lleno en el ámbito de lo valorativo y axiológico, vedado inexorablemente al Órgano judicial, que tendrá que actuar con un pleno criterio de relativismo, en atención al caso concreto y circunstancias concurrentes. Ahora bien, esto no significa que el Órgano judicial tenga que hacer una ponderación de intereses, sino que tendrá que determinar cuál es el límite de lo tolerado o permitido. En este sentido, cuanto más aprecie la sociedad la utilidad de una determinada actividad, más riesgos estará dispuesta a aceptar. En numerosas ocasiones los niveles de permisividad de un riesgo determinado se halla en correlación directa con el avance tecnológico de un país y el estado de desarrollo de la ciencia; de ahí que algunos riesgos que antes eran prácticamente imposibles de permitir lleguen en un momento determinado a ser tolerados por el Ordenamiento jurídico.

El concepto de riesgo permitido implica que, además de los fines que se persiguen con una determinada actividad, hay que aceptar otra serie de consecuencias que no se persiguen. No obstante, lo que tolera la norma penal no son algunos niveles de riesgo, sino la configuración de determinadas conductas que conllevan inherentemente ciertos riesgos. Como señala BERNARDO FEIJÓO28, no cabe hablar de un límite matemático o un nivel cuantitativamente fijo de riesgo cuyo traspaso determine la inter- 
vención del Derecho penal. En este sentido, si una conducta se puede calificar como cuidadosa, el riesgo que la misma conlleve será tolerado por la norma penal, independientemente de la probabilidad de la lesión, mientras que si la conducta es descuidada ese riesgo ya no podrá ser tolerado.

En definitiva, el instituto del riesgo permitido es un elemento clave para imputar una responsabilidad por imprudencia, ya que sirve para valorar si ha existido una infracción del deber de cuidado, de no producirse dicha infracción no se podrá imputar un resultado a título de imprudencia; de ahí su importancia.

En nuestra sociedad cada vez existe una mayor planificación de riesgos en ámbitos especialmente peligrosos. De hecho, el Estado interviene de un modo intenso en actividades peligrosas con el fin de conseguir una estandarización mínima como medio para prevenir ciertos riesgos.

\section{Iv.1.Riesgos en ámbitos profesionales con un estándar técnico : el estándar médico o lex artis en el caso de la medicina}

Uno de los ejemplos más característicos de profesión carente de normas jurídicas de regulación, donde el Ordenamiento jurídico no tiene otra solución que acudir al estándar técnico, o a la opinión mayoritaria de los especialistas del ramo, como indicio para determinar el deber de cuidado, es la actividad médico-quirúrgica.

En este ámbito profesional, dado que se encuentra en continuo desarrollo científico ${ }^{30}$, el Ordenamiento jurídico no puede establecer normas de actuación, ya que quedarían rápidamente obsoletas, además de la imposibilidad material de compendiar en normas jurídicas conocimientos tan prolijos como los de la Ciencia médica.

Consecuentemente, el Tribunal a la hora de valorar si el facultativo ha actuado dentro del riesgo permitido o, si por el contrario, ha infringido el deber de cuidado, por extralimitarse en dicho riesgo, tendrá que valerse del denominado estándar médico ${ }^{31}$. Este término no tiene una significación distinta a la lex artis ${ }^{32}$, cuyo uso es más habitual y representa el conjunto de reglas de la técnica vigentes en la profesión médica. En este sentido, tanto si se usa el término estándar médico como si se habla de lex artis, la observancia de la medicina debe realizarse en el momento en que se efectúa la intervención. Asimismo, el Tribunal deberá valorar otras circunstancias concretas como el lugar y el tiempo en que se efectúa dicha intervención ${ }^{33}$, teniendo en cuenta no sólo los medios con que cuenta el profesional sanitario, sino también la urgencia de la misma, o las posibilidades de traslado a un centro con más recursos ${ }^{34}$. La concurrencia de todas estas variables en la determinación del estándar médico o lex artis conforman la denominada lex artis ad hoc ${ }^{35}$.

En el ámbito médico son de suma importancia los Protocolos y las Guías clínicas de actuación, en la medida que conforman la lex artis propiamente dicha. Son criterios científicos universales de actuación, realizados de conformidad con la evolución de la tecnología y la práctica médica o evolución de la ciencia ${ }^{36}$.

Así, por ejemplo, una actuación correcta en anestesiología se debe realizar de conformidad con los parámetros y estándares de la práctica clínica de esta especialidad. Éstos exigen inicialmente una evaluación preanestésica, que comprende: 1. La revisión de la historia clínica, que incluye datos objetivos diagnóstico (laboratorio, radiología etc) y revisión de hojas anteriores de anestesia, cuando sean pertinentes y estén disponibles; 2 . Entrevista con el paciente, incluyendo historia de medicaciones y alergias, historia familiar de problemas anestésicos, hábitos (tabaco, alcohol etc.) ${ }^{37}$.

La omisión ${ }^{38}$ de estas actividades previas, exigidas por el estándar médico o lex artis, conlleva la infracción del deber objetivo de cuidado, traducido en la creación de un riesgo no permitido. En este caso, si se produce un resultado de muerte o lesiones, en directa relación de causalidad que exige la teoría de la imputación objetiva, surgirá una responsabilidad por imprudencia médica ${ }^{39}$.

Otros de los parámetros en base a los que se debe practicar una correcta anestesiología son los estándares de anestesia para monitorización básica introperatoria, cuyo objetivo es la seguridad del paciente y la calidad de la anestesia. Este estándar establece la obligación de la presencia del anestesiólogo durante la realización de cualquier procedimiento de anestesia general o local, no pudiendo ser nunca reemplazada por la monitorización ${ }^{40}$. Además, deberá contar con la ayuda de personal de enfermería experimentado en los momentos que sea necesario.

Pese a las obligaciones impuestas por dicho estándar, no son escasos los supuestos de imprudencias sanitarias ${ }^{41}$ con resultado de lesiones o muerte por ausentarse el anestesista en una operación quirúrgica ${ }^{42}$. En primer lugar, debemos precisar, siguiendo a SILVA SÁNCHEZ ${ }^{43}$, que el anestesista, en el cumplimiento de las obligaciones que le competen, es autónomo antes, durante y después de la operación quirúrgica ${ }^{44}$, mientras que el cirujano es competente para la decisión sobre el si, el cómo y el cuándo de la operación. Las competencias de cada uno quedan articuladas en base al denominado principio de confianza ${ }^{45}$. Ahora bien, excepcionalmente, cuando se produce una infracción del deber de cuidado por el anestesista, por ejemplo, o surgen dudas sobre su cualificación o fiabilidad, aparece un deber de cuidado, cuyo incumplimiento puede llevar a imputar el resultado lesivo al cirujano ${ }^{46}$.

Como colofón, para valorar si ha existido una infracción del deber de cuidado en el campo de la medicina, ámbito con una lex artis bastante estandarizada, podemos destacar, a modo de conclusiones, lo siguiente: 1 . La responsabilidad médica debe, en principio, ser proclamada cuando en el tratamiento médico, terapéutico o quirúrgico se incida en conductas descuidadas, que olvidando la lex artis, provoquen resultados lesivos; 2 . Si el facultativo utiliza alguno de los remedios, técnicas o terapias admitidos como lex artis habrá actuado diligentemente; 3 . La "libertad de tratamiento", "libertad de terapia" o "libertad de método" debe ser utilizada por el facultativo dentro de las coordenadas de la lex artis, de lo contrario infringirá el deber de cuidado. 


\section{Bibliografía citada}

- BERNARDO FEIJÓO: Resultado lesivo e imprudencia, Barcelona, 2001.

- CORCOY BIDASOLO, M.: El delito imprudente. Criterios de imputación del resultado, Barcelona, 1989.

- CHOCLÁN MONTALVO, J. A.: Deber de cuidado y delito imprudente, Barcelona, 1998.

- GALÁN CORTES, J.: "La responsabilidad civil y penal del médico anestesista", en La Ley, 1995, pp. 1055-1073.

- GÓMEZ PAVÓN, P.: Tratamientos médicos: su responsabilidad penal y civil, $2^{\mathrm{a}}$ ed., Barcelona, 2004.

- JORGE BARREIRO, A.: La imprudencia punible en la actividad médico-quirúrgica, Madrid, 1990, p. 49.

- LÓPEZ TIMONEDA, en Responsabilidad del personal sanitario (actas del seminario conjunto sobre la responsabilidad del personal sanitario, celebrado en Madrid los días 14, 15 y 16 de noviembre de 1994), Consejo General del Poder Judicial. Ministerio de Sanidad y Consumo, Madrid, 1995, pp. 59-70.

- MARTINEZ-CALCERRADA, L.: "Especial estudio de la denominada "lex artis ad hoc" en la función médica", en Actualidad Civil, 1986-1, pp. 1697-1709.
- MARTINEZ-PEREDA RODRIGUEZ, J. M.: La responsabilidad del médico y del sanitario, Madrid, 1990. Del mismo: MARTINEZ-PEREDA, J. M.: "La imprudencia punible del anestesista según la doctrina del Tribunal Supremo", en Actualidad Penal, 1994.1., pp. 283-291.

- ROMEO CASABONA, C. M.: El médico y el Derecho penal, Barcelona, 1981.

- SILVA SÁNCHEZ, J.M.: "Aspectos de la responsabilidad penal por imprudencia de médico anestesista. La perspectiva del Tribunal Supremo", en Derecho y Salud, vol. 2, núm. 2, julio-diciembre 1994, pp. 5769. Del mismo: "La responsabilidad penal del médico por omision", en La Ley, 1987, pp. 955-966.

- SOLA RECHE, E./HERNÁNDEZ PLASENCIA, J. U./ROMEO CASABONA, C. M.: "La responsabilidad profesional del médico en el Derecho español", en Responsabilidad penal y responsabilidad civil de los profesionales, XXII Coloquio de Derecho europeo, Universidad de La Laguna, 1993, pp. 99-120.

- VILLACAMPA ESTIARTE, C.: Responsabilidad penal del personal sanitario, Navarra, 2003.

1 No obstante, conviene recordar que no toda imprudencia es relevante penalmente, tan sólo aquéllas que el legislador ha seleccionado, lo que significa que únicamente existirán delitos imprudentes en aquellos supuestos que la propia Ley indique. Con la dicción del artículo 12 del Código penal de 1995: "las acciones u omisiones imprudentes sólo se castigarán cuando expresamente lo disponga la Ley", se establece un sistema de numerus clausus, quedando así eliminada la cláusula general o numerus apertus del sistema anterior, en el que se basaba la incriminación de los delitos imprudentes. Son numerosas las obras doctrinales sobre esta materia, entre otras, destacamos: CHOCLÁN MONTALVO, J. A.: Deber de cuidado y delito imprudente, Barcelona, 1998; CORCOY BIDASOLO, M.: El delito imprudente. Criterios de imputación del resultado, Barcelona, 1989. En sede jurisprudencial, sobre los elementos que la comisión de un delito imprudente exige, véanse, a título de ejemplo, SSTS de 16 de junio de 1987, 14 de septiembre de 1990, 24 de octubre de 1994, 25 de mayo de 1999, 23 de octubre de 2001 y 19 de julio de 2002.

2 STS de 13 de febrero de 1997.

3 Ya en la STS de 14 de febrero de 1991 se requiere "el daño o perjuicio concreto, sobrevenido como consecuencia de aquella conducta negligente, en su doble vertiente de falta de previsión o "deber de saber" y la falta de cuidado o "deber de evitar" añadiendo, a su vez, que "entre la actuación negligente y el resultado dañoso ha de mediar la correspondiente relación de causalidad, de causa a efecto, lo que a su vez generará la responsabilidad cuando el reproche sea imputable a persona determinada".

4 El legislador del Código penal de 1995 ha sustituido las figuras legales de imprudencia temeraria e imprudencia simple por las de grave y leve, otorgando a la primera el rango de delito, en el caso que nos ocupa arts. 142, 152 y 158, y reservando para la forma leve la sanción de falta, en este sentido art. 621.2 y 3 . Ahora bien, esta correlación imprudencia grave-delito e imprudencia leve-falta se quiebra en el supuesto de las lesiones del art. 147.2 , ya que si son causadas por imprudencia grave no se sancionan como delito sino como falta prevista en el art. 621.1 del Código penal.

5 Es doctrina reiterada de la Sala Segunda del Tribunal Supremo, entre otras SS de 28 de enero, 13 de noviembre y 13 de junio de 1981, 22 de abril de 1988, y 27 de noviembre de 2001 , que las líneas divisorias de los diferentes grados de la imprudencia punible son tenues e imprecisos, ya que dependen de las circunstancias concurrentes. De ahí la importancia, como señala la citada STS de 22 de abril de 1988 de "que las Audiencias no pequen de una excesiva sobriedad al narrar o describir lo sucedido, sino que en el "factum" de sus sentencias, no regateen ni escatimen datos o pormenores sino que lo redacten minuciosamente y con toda prolijidad posible, facilitando, de ese modo, y haciendo funda- 
da y comprensible la delimitación, así como la calificación más certera y atinada".

6 STS de 28 de enero de 1981. Como destaca la STS de 10 de octubre de 1998 "el texto vigente elude toda referencia a la infracción de reglamentos en la fijación de los criterios legales de la imprudencia, lo que ha sido saludado positivamente por la doctrina, en la medida que las previsiones reglamentarias pueden no corresponderse "per se" con las normas de cuidado, como ya había puesto de manifiesto la doctrina jurisprudencial".

7 Así, la desatención normal o debida, representando la infracción de un deber de cuidado de pequeño alcance, aproximándose, sin alcanzarla, a la cota exigida habitualmente en la vida social, conllevaba una imprudencia simple con o sin infracción de reglamentos (STS de 14 de septiembre de 1990), mientras que si se dejaba de prestar la atención más elemental o indispensable, o bien existía omisión absoluta del deber de atención, se incurría en imprudencia temeraria (SSTS de 13 de marzo de 1982, 29 de marzo de 1988 y 28 de diciembre de 1990). Sobre la diferencia entre las antiguas categorías legales de simple imprudencia o negligencia sin infracción de reglamentos e imprudencia simple con infracción de reglamentos, véanse las SSTS de 13 de diciembre de 1974, 14 y 23 de abril de 1975,14 de febrero, 3 de mayo y 18 de diciembre de 1978, 26 de abril de 1979, 9 de diciembre de 1981, 4 de julio de 1983, 22 de diciembre de 1984, 18 de diciembre de 1985, 13 de febrero de 1986 y 29 de marzo y 22 de abril de 1988.

8 La actual figura de imprudencia grave se corresponde con la antigua imprudencia temeraria, esto es, con la más grave infracción del deber objetivo de cuidado, mientras que la imprudencia leve coincide con la anterior imprudencia simple, que en la modalidad de simple sin infracción de reglamentos, como destaca, con gran acierto, la STS de 10 de octubre de 1998 "prácticamente habría que estimarla situada extramuros del sistema penal, alojada dentro del Ordenamiento civil como respuesta más acorde con el principio de intervención mínima".

9 STS de 10 de octubre de 1998.

10 SSTS de 11 de octubre de 1979, 19 de febrero de 1982 y 29 de marzo de 1988.

11 La imprudencia profesional apareci6 en el Código penal de 1944 limitada a las infracciones cometidas con vehículo de motor. Con la revisión del Código penal por Ley de Bases de 23 de diciembre de 1961 se eliminó esta circunscripción al ámbito automovilístico, otorgando a la imprudencia profesional un carácter general cuando se produjera muerte o lesiones graves a consecuencia de impericia o negligencia profesional. Sobre la imprudencia profesional, véase por todos, MARTINEZ-PEREDA RODRIGUEZ, J. M.: La responsabilidad del médico y del sanitario, Madrid, 1990, pp. 55-83.

12 Este cambio puede observarse, sobre todo, a partir de la STS de 30 de septiembre de 1959. Sobre la restricción en la aplicación de la agravante de imprudencia profesional indica la STS de 26 de abril de 1984 que "la culpa de un profesional anestesista no entraña, por sí sola, la impericia o negligencia profesional que, como agravante específica, se recoge en el párrafo segundo del artículo 565 del Código penal". En el mismo sentido, la STS de 24 de noviembre de 1989 señala que "para la difícil tarea de diferenciar culpa del profesional y culpa profesional, la jurisprudencia ha venido a sentar al menos un claro criterio inspirador: el respeto al artículo 9.3 de la Constitución española exige evitar que se eleve a la categoría de ordinaria una agravación que legalmente aparece como excepcional".

13 La STS de 1 de diciembre de 1981 condena al Jefe de sección de anestesia de un Centro médico hospitalario como autor de un delito de imprudencia temeraria por negligencia profesional, con resultado de muerte. Reza la sentencia que "la culpa debe recibir el calificativo de profesional cuando el resultado, al cual debe ir ligada por relación causal inexcusable, se produzca a consecuencia de un acto profesional que sea en sí mismo imperito o negligente, dentro de la estructura de la actividad que en cada caso corresponde, es decir, un comportamiento incompatible con la profesión, con grave vulneración de las reglas llamadas de la lex artis". Abundando aún más la STS de 22 de abril de 1988 señala que en la culpa profesional "el infractor incurre en un plus de antijuridicidad consecutivo a la inobservancia de la lex artis y de las precauciones y cautelas más elementales, siendo totalmente imperdonable e indisculpable que una persona que pertenece a la profesión o actividad de que se trate (...) proceda de un modo ignaro e indocto, mostrando ignorancia suma de las reglas fundamentales del ejercicio profesional". La más reciente jurisprudencia se ha pronunciado en términos similares, así la STS de 27 de marzo de 2002, reproduciendo el contenido de la STS de 3 de octubre de 1997, establece que "la imprudencia profesional (relacionada con una intervención médica) se caracteriza por la inobservancia de las reglas de actuación, que vienen marcadas por lo que se conoce, en términos jurídicos, como lex artis, lo que conlleva un plus de antijuridicidad que explica la elevación penológica (...) La imprudencia profesional aparece claramente definida en aquellos casos en que se han omitido los conocimientos específicos que sólo tiene el sujeto por su especial formación". La misma doctrina aparece recogida en SSTS de 8 de junio de 1994, 25 de mayo y 8 de noviembre de 1999 y 26 de febrero 2001 . Además de la citada STS de 
27 de marzo de 2002, otros ejemplos de fallo condenatorio por imprudencia profesional, en el ámbito médico, son la SSTS de 23 de octubre de 2001 y 19 de julio de 2002.

14 Señala la STS de 29 de marzo de 1988 que la culpa del profesional significa "imprudencia o negligencia comunes cometidas por aquél en el ejercicio de su arte u oficio". Una reiterada jurisprudencia ha abundado en la distinción entre "culpa profesional" y "culpa del profesional" (SSTS de 2 de enero y 24 de marzo de 1984, 23 de febrero y 30 de septiembre de 1985, 21 de febrero de 1986, 23 de julio de 1987, 29 de marzo y 27 de mayo de 1988, 5 de julio y 1 de diciembre de 1989, 24 de enero de 1990, 22 de septiembre de 1992, 7 de julio de 1993, 8 de junio de 1994, 21 de julio de 1995, 8 de mayo de 1997 y 16 de diciembre de 1997).

15 En efecto, en caso de imprudencia profesional se aplicará la pena correspondiente a cada uno de los supuestos previstos en el artículo 152.1 del Código penal y, además, como establece el art. 152.3, "se impondrá asimismo la pena de inhabilitación especial para el ejercicio de la profesión, oficio o cargo por un periodo de uno a cuatro años".

16 Así lo han declarado las SSTS de 28 de septiembre de 1987 y 29 de octubre de 1994. En el mismo sentido, SILVA SÁNCHEZ, J.M.: "Aspectos de la responsabilidad penal por imprudencia de médico anestesista. La perspectiva del Tribunal Supremo", en Derecho y Salud, vol. 2, núm. 2, julio-diciembre 1994, p. 68, ha puesto de relieve la dificultad de distinguir entre imprudencias profesionales e imprudencias no profesionales, esto es, comunes de los profesionales, lo que conlleva, como consecuencia lógica, que la jurisprudencia no aplique coherentemente su propio criterio distintivo, valga de ejemplo las SSTS de 26 de junio de 1980, 7 de julio de 1993 o 18 de noviembre de 1991.

17 En este sentido, el artículo 565.2 del Código penal de 1973 preceptuaba: "Cuando se produjere muerte o lesiones con los resultados previstos en los artículos 418, 4196421 .2, a consecuencia de impericia o negligencia profesional, se impondrán en su grado máximo las penas señaladas en este artículo. Dichas penas se podrán elevar en uno o dos grados a juicio del Tribunal, cuando el mal causado fuere de extrema gravedad". Así, pues, el Código penal de 1973 utilizaba junto al término "imprudencia" también los de "negligencia" e "impericia", términos que fueron eliminados por el legislador del Código penal de 1995. No obstante, señala GÓMEZ PAVÓN, P.: Tratamientos médicos: su responsabilidad penal y civil, $2^{\mathrm{a}}$ ed., Barcelona, 2004, p. 341 , que la doctrina mayoritaria no ha distinguido entre impericia o negligencia, reconduciendo ambas a la falta de aptitud o actitud descuidada del profesional en el ejercicio de su profesión. Sobre este extremo, matizan SOLA RECHE, E./HERNÁNDEZ PLASENCIA, J. U./ROMEO CASABONA, C. M.: "La responsabilidad profesional del médico en el Derecho español", en Responsabilidad penal y responsabilidad civil de los profesionales, XXII Coloquio de Derecho europeo, Universidad de La Laguna, 1993, p. 103, que el Código penal se refería con estas expresiones a la asunción de un riesgo excesivo, no permitido, infringiendo con ello unos deberes de cuidado, sin perjuicio de algunas diferencias de matiz cuando se trata de impericia y negligencia en el campo profesional, en otro caso, imprudencia y negligencia son términos sinónimos.

18 En idénticos términos se han pronunciado las SSTS de 5 de julio de 1989 y 29 de febrero de 1996.

19 SSTS de 10 de marzo de 1959 y 17 de julio de 1982.

20 SSTS de 8 de octubre de 1963, 10 de abril de 1970, 30 de abril de 1979, 26 de octubre de 1981, 26 de octubre de 1983, 24 de noviembre de 1984, 7 de octubre y 22 de diciembre de 1986, 29 de marzo de 1988, 5 de mayo y 5 de julio de 1989 y 14 de febrero de 1991 .

21 STS de 10 de marzo de 1959, 8 de octubre de 1963,5 de febrero y 8 de junio de 1981 .

22 STS de 5 de julio de 1989. Señala sobre el particular la STS de 26 de junio de 1980 , que el otorgamiento de un título profesional, de conformidad con la normativa académica, crea una presunción de competencia que encuentra su fase negativa en la impericia, "entendiendo por tal la incapacidad técnica para el ejercicio de la profesión de que se trate, y esa impericia puede encontrar su fundamento causal en la ignorancia o en la defectuosa ejecución del acto requerido por la Lex artis".

23 STS de 16 de abril de 1970,26 de junio y 25 de noviembre de 1980,5 de febrero y 8 de junio de 1981.

24 STS de de 26 de junio y 25 de noviembre de 1980,5 de febrero y 8 de junio de 1981 y 25 de enero de 1988.

25 STS de 8 de junio de 1981.

26 STS de 5 de mayo de 1989.

27 Este último principio general ha sido extraído de la STS de 1 de diciembre de 1989, que también hace referencia a la doctrina del Alto Tribunal sobre la responsabilidad penal de los médicos.

28 BERNARDO FEIJÓO: Resultado lesivo e imprudencia, Barcelona, 2001, p. 272.

29 Sobre este extremo, señala BERNARDO FEIJÓO: Resultado lesivo e imprudencia, cit., pp. 307 y ss., que estándar técnico no es lo mismo que riesgo permitido, por cuanto dicho 
estándar no responde a una aceptación colectiva, sólo a la opinión mayoritaria de los especialistas del ramo que lo han creado, lo utilizan o se benefician de dicho riesgo. En definitiva, el estándar técnico es de gran utilidad en la medida que sirve como instrumento de control del riesgo, pero ello no significa que el Ordenamiento jurídico lo haya tolerado, ya que no coincide ni en el fundamento ni en la legitimidad con el riesgo permitido.

30 También se ha pronunciado nuestro más Alto Tribunal sobre la problemática de la constante evolución de la Ciencia médica. Así, la STS de 26 de junio de 1980 establece como regla general "lo aventurado que significa el querer sentar como apotegma principios inmutables, debido, de una parte, al progreso constante en este campo". En idénticos términos se han pronunciado las SSTS de 15 de enero de 1986, 29 de marzo de 1988, que destaca la importancia de prestar cuidadosa atención a la lex artis, "sin sentar apotegmas absolutos, dada la evolución constante de la Ciencia médica" y 14 de febrero de 1991. Como señala la STS de 4 de septiembre de 1991 que, como ya hemos destacado, recoge una elaborada doctrina sobre la imprudencia médica, en esta materia no existen principios inmutables, ya que no se pueden realizar generalizaciones, sino que, por el contrario, se precisa una individualizada reflexión sobre el concreto supuesto enjuiciado.

31 Este término, cuyo uso ya es generalizado entre los juristas alemanes, comienza a ser utilizado por la doctrina penal española.

32 Sobre la lex artis, literalmente "ley del arte", ley artesanal o regla de la técnica de actuación de la profesión en cuestión, señala LÓPEZ TIMONEDA, en Responsabilidad del personal sanitario (actas del seminario conjunto sobre la responsabilidad del personal sanitario, celebrado en Madrid los días 14, 15 y 16 de noviembre de 1994), Consejo General del Poder Judicial. Ministerio de Sanidad y Consumo, Madrid, 1995, p. 59, que "la lex artis se refiere a una serie de reglas técnicas siguiendo los estándares aceptados y aprobados en el ejercicio de la profesión, teniendo en cuenta las circunstancias y condiciones en que hubieron de efectuarse y la situación del paciente en cada caso; en definitiva, es hacer bien las cosas o realizar una actuación profesional correcta".

33 Sobre la importancia de valorar las circunstancias concretas de lugar y tiempo en el que se realiza la actividad médico-quirúrgica, cfr. JORGE BARREIRO, A.: La imprudencia punible en la actividad médico-quirúrgica, Madrid, 1990, p. 49; ROMEO CASABONA, C. M.: El médico y el Derecho penal, Barcelona, 1981, pp. 245-247.

34 VILLACAMPA ESTIARTE, C.: Responsabilidad penal del personal sanitario, Navarra, 2003, p. 37.

35 Término acuñado por MARTINEZ-CALCERRADA, L.: "Especial estudio de la denominada "lex artis ad hoc" en la función médica", en Actualidad Civil, 1986-1, pp. 16971709. Este autor define este término como "el criterio valorativo de la corrección del concreto acto médico ejecutado por el profesional de la medicina, ciencia o arte médica, que tiene en cuenta las especiales características de su autor, de la profesion, de la complejidad y trascendencia vital del acto y, en su caso, de la influencia en otros factores endógenos, estado e intervención del enfermo, de sus familiares o de la misma organización sanitaria, para calificar dicho acto de conforme o no con la técnica normal requerida (derivando de ello tanto el acervo de exigencias o requisitos de legitimación o actuación lícita, de la correspondiente eficacia de los servicios prestados y, en particular, de la posible responsabilidad de su autor/médico por el resultado de su intervención o acto médico ejecutado") (p. 1700).

36 Estos criterios de estandarización mínima han sido recogidos por LÓPEZ TIMONEDA, en Responsabilidad del personal sanitario, pp. 59 y ss.

37 "La correcta asistencia anestesiológica del paciente quirúrgico constituye una verdadera cadena asistencial que comienza con la preanestesia (consulta preanestésica), continua con la técnica anestésica, propiamente dicha, y no finaliza hasta el despertar del paciente en la unidad de recuperación postanestésica (URPA) 6 unidad de reanimación; siendo todo este proceso de la competencia y responsabilidad exclusiva del médico especialista en anestesiología-reanimación". Cfr. LÓPEZ TIMONEDA, en Responsabilidad del personal sanitario, cit., p. 61,

38 Cfr. SILVA SÁNCHEZ, J. M.: "La responsabilidad penal del médico por omisión", en La Ley, 1987, pp. 955-966.

39 Valga de ejemplo la STS de 7 de diciembre de 1993 que declar6 como hechos probados "a) El desconocimiento por el facultativo del grupo sanguíneo de la niña a la que practicó la intervención quirúrgica. b) La ausencia de análisis sanguíneos encaminados o dirigidos al diagnóstico de anemia (...) c) Que la niña fallecida tenía el grupo sanguíneo B y fue transfundida con plasma del grupo $\mathrm{O}$ y factor $\mathrm{RH}$ negativo (...)". La sentencia condena por imprudencia al facultativo que "no agotó las medidas de cuidado exigibles (...) por lo demás de rápida y fácil realización, como la comprobación analítica de la existencia de anemia, la del grupo sanguíneo del paciente (...)". Igualmente, la STS de 18 de marzo de 1993 condena por imprudencia temeraria al médico que no realiz 6 las previas y 
oportunas pruebas alérgicas, y la STS de 9 de marzo de 2000, si bien no condena por imprudencia temeraria, puesto que el médico se informó de las posibles alergias a medicamentos por parte del fallecido, sin embargo si lo hace por simple imprudencia o negligencia, ya que el interrogatorio debió ser más completo e intenso.

40 Sobre la importancia de extremar al máximo la cautela y precaución en el acto de la anestesia se han pronunciado, entre otras muchas, las SSTS de 22 de abril de 1988 y 4 de septiembre de 1991.

41 Son varios los estudios realizados por la doctrina sobre la responsabilidad penal por imprudencia del médico anestesista. Por su interés destacamos, entre otros, los siguientes: MARTINEZ-PEREDA, J. M.: "La imprudencia punible del anestesista según la doctrina del Tribunal Supremo", en Actualidad Penal, 1994.1., pp. 283-291; GALÁN CORTES, J.: "La responsabilidad civil y penal del médico anestesista", en La Ley, 1995, pp. 10551073; SILVA SÁNCHEZ, J.M.: "Aspectos de la responsabilidad penal por imprudencia de médico anestesista. La perspectiva del Tribunal Supremo", cit., pp. 57-69.

42 La STS de 1 de diciembre de 1989 condena como autor de un delito de imprudencia temeraria con resultado de muerte al Jefe de sección de anestesia, que intervino en una operación quirúrgica en calidad de médico anestesista. Como relación de hechos señala la sentencia que el acusado "abandonó el quirófano sin dar cuenta a nadie durante diez minutos, por lo que tuvo que ser avisado por la ATS para que volviese a su puesto por haberse movido el enfermo para normalizar la situación. No obstante, volvió a ausentarse del quirófano de nuevo y hubo de ser buscado por la enfermera y tras una tercera ausencia de más de diez minutos cuando volvió de nuevo a su puesto en la operación (...) descubrió que el tubo nasotraqueal que suministraba oxígeno al paciente estaba desconectado, lo que provocó a la víctima el que quedara descerebrada y en estado crónico vegetativo, hasta su posterior fallecimiento". También resulta de interés referirnos a las SSTS de 7 de julio de 1993 y 18 de septiembre de 1989, condenando esta última por imprudencia al médico anestesista y a la enfermera que abandonaron la sala de despertar, falleciendo el paciente. Una condena similar se recoge en la STS de 26 de abril de 1994, donde el médico anestesista abandona la sala de despertar, sin que el paciente hubiera recuperado la conciencia, para asistir a otra operación durante media hora, tiempo durante el cual el paciente no estuvo vigilado ni controlado por otro facultativo.

43 SILVA SÁNCHEZ, J.M.: “Aspectos de la responsabilidad penal por imprudencia de médico anestesista. La perspectiva del Tribunal Supremo", cit., pp. 57 y 58.

44 Así también lo ha declarado la STS de 7 de julio de 1993, al consignar que "ni el conocimiento y consentimiento del cirujano-jefe de su ausencia sirve de causa exculpadora porque el anestesista asume, dentro del equipo médico de que forma parte, con plena autonomía y responsabilidad, todas las funciones que son de su competencia y atinentes a su especialidad".

45 El principio de confianza despliega su eficacia en aquellos casos donde con la actuación infractora de un sujeto se entremezclan otros participantes en la actividad en cuestión, a quienes también abarcará el peligro creado por dicha infracción. Cfr. Sobre este principio, CORCOY BIDASOLO, M.: El delito imprudente. Criterios de imputación del resultado, cit., pp. 327 y ss.

46 Así, por ejemplo, en un supuesto de operación quirúrgica donde el anestesista se ausenta por tener que atender simultáneamente a dos pacientes operados en quirófanos distintos, la STS de 11 de octubre de 1979 condena al Jefe de equipo por incurrir en la falta de atención que le era exigida, al no percatarse del estado cianótico de la víctima, y conocer y consentir tácitamente la ausencia del anestesista. Un supuesto similar ha sido enjuiciado por el Tribunal Supremo en Sentencia de 4 de septiembre de 1991, señalando que "el cirujano a quien corresponde una específica actividad sobre el paciente, conoce y tiene el deber de conocer los riesgos de las operaciones con anestesia general. Si tolera que no se conecte el aparato monitor y no lo conecta él y además permite la ausencia del anestesista consiente en su actuación quirúrgica un estado de riesgo determinante en adecuada relación causal del resultado final del fallecimiento del paciente". Como reza la STS de 24 de noviembre de 1989 "el procesado debió percibir el peligro que el acto médico y las negativas condiciones implicaba para la vida del paciente. La conducta imprudente del recurrente comienza por no controlar la conexión del monitor al inicio de la operación y en su tolerancia o consentimiento a que el anestesista abandonase el quirófano". Ha sido constante la doctrina de la Sala Segunda del Tribunal Supremo a la hora de exigir al cirujano, por su condición de experto, la obligación de conocer los riesgos que se producen en las intervenciones quirúrgicas efectuadas con anestesia general, SSTS de 26 de junio de 1980,19 de febrero, 11 de junio de 1982 y 22 de abril de 1988 . 